children. Thirteen per cent felt that the children had suffered from the parents' limited physical participation in family activities, for example holidays. Interestingly, $10 \%$ felt that their children had 'benefited' in that they had become more caring with heightened common sense and sensitivity, although $14 \%$ did concede that excess stress had been induced. There was a perceived sense of inertia from the multiple sclerosis sufferers' point of view: 'They have become carers, which I don't like but I am powerless to stop it'

Caring is a complex phenomenon for families which does not always need to be replaced by the statutory or voluntary agencies. It appears, for the younger physically adult, to be the rule rather than the exception and it requires recognition, careful appraisal, and possible proactive intervention.

IAIN SMITH Nuffield Institute for Health, University of Leeds, clo Bradford Health Authority New Mill, Victoria Road,

Saltaire,

Shipley

$B D 183 L D$

JULIA FARRAR Multiple Sclerosis Needs Assessment Project, Bradford Health Authority

1 Aldridge J, Becker S. Children as carers. Arch Dis Child 1993; 69: 459-62.

\section{Availability of data tapes from national infant feeding surveys in 1985 and 1990}

EDITOR,-The first national survey of infant feeding practices was in 1975 . These surveys have been repeated every five years and are internationally acclaimed. They offer unique high quality information about how this country feeds its infants. The first survey covered England and Wales only, Scotland has been included from 1980, and in 1990 Northern Ireland has also joined in. Some 6000 new mothers, chosen as nationally representative of their population, provide information on three occasions: at 6 weeks, at 4 months, and at 9 months after their baby was born. Apart from gathering facts, the questionnaires are designed to draw out information about influences on the parents' choices of how to feed their baby. The scope and style of the surveys can best be assessed by referring to the report of the most recent survey, which was published in 1992.1

The surveys were conducted by the Office of Population Censuses and Surveys for the Department of Health. Readers may wish to be aware that the full data tape of the surveys in 1985 and 1990 is now available for independent researchers. It has become standard practice for the data tapes from diet and nutrition surveys to be deposited with the National Data Archive. Access to this information is available on request to this address: ESRC Data Archive, University of Essex, Wivenhoe Park, Colchester, Essex CO4 3SQ (Tel: 0206 872001).

\section{BOOK REVIEWS}

ABC of One to Seven. 3rd Ed. By $\backslash \mathrm{H} B$ Valman. (Pp 144; $£ 8.95$ paperback.) BMJ Publishing Group, 1993. ISBN 0-72790768-9.

This book aims to be a practical guide to paediatrics for GPs, medical students, vocational trainees, nurses, and midwives. Based on a series of $B M \mathcal{F}$ articles and first published in 1982 it has achieved deserved popularity because it is easy to read, profusely illustrated, and memorable. It packs most of the important topics of primary care paediatrics into its 144 pages.

The third edition has a new chapter on audit, examples of pamphlets for parents, and forms for recording results of child health surveillance, as well as revisions of several chapters. Many paediatricians would not, I think, agree that swimming should be avoided after insertion of grommets, or that steam inhalation often helps acute stridor. The statement that children with epilepsy should not ride a bicycle on the open road is at odds with the advice of the British Epilepsy Association. The emphasis on admission to hospital in the management of child abuse is surprising in the light of current practice and the Children Act.

This is a shame because many chapters are well written, informative, and up to date. Asthma, urinary tract infection, abdominal pain, minor orthopaedic problems, and sleep and behaviour problems are all well covered with plenty of sound commonsense advice for parents as well as practitioners.

The four chapters on services for children, in primary care, the community, outpatient clinics and day care, in accident and emergency departments, and finally in hospital clearly describe the respective roles of each part of the service and offer models of good practice.

This $A B C$ will continue to attract a wide readership simply because it is readable, cheap, and deals with common paediatric problems in a practical way. Its A4 size makes it a difficult book to handle as a study or bedtime read. It is more likely to be found on the mess coffee table where it will attract the passing trainee with a few minutes to spare while waiting for the next patient or episode of Neighbours. With any luck the author's evident enthusiasm will encourage him to read on.

K L DODD

Consultant paediatrician

Phototherapy. Treating Neonatal Jaundice with Visible Light. Edited by $\mathrm{K}$ Jährig, D Jährig, and P Meisel. (Pp 193; £35 hardback.) Quintessence Publishing Co Ltd, 1993. ISBN 3-86128-113-9.

This is a rather unusual monograph devoted to phototherapy for neonatal jaundice. Its first edition appeared in 1980 and was written in German. This expanded version has both
German and English editions and the original authors from Greifswald (formerly East Germany) have been joined by two contributors from Italy and one from Norway. I am not sure who was responsible for the translation from German but 'it can thus be stated that every hyperbilirubinaemia is a condition requiring treatment and, apart from its aetiology, the only question to be discussed is the limits of the indication', needs some clarification.

The book is packed with information, some of which is useful and some much less so. Generally the clinical section is more helpful than basic physical principles, but the authors come over as dedicated advocates of phototherapy: 'phototherapy is recommended for infants with levels exceeding $10 \mathrm{mg} / \mathrm{d}$ $(170 \mu \mathrm{mol} / \mathrm{l})$ up to the 5 th day of life'. None of the 'lighter touch' here. 'To what extent bilirubin is of physiological importance as a scavenger of oxygen radicals in the neonatal period and whether it helps to prevent cerebral damage by oxygen radicals precisely during the treatment of newborns with hypoxia, is too speculative at present for any new therapeutic conclusions to be drawn from it'. In other words phototherapy is unlikely to be harmful so if in doubt treat. If the reader wants to obtain a flavour of the recommendations of this monograph he could turn to $p$ 155-9; Summary: phototherapy in the approach to the treatment of neonatal jaundice.

Recommended for reference in the local medical library rather than to buy.

H L HALLIDAY Consultant paediatrician

Pediatric Respiratory Disease. Diagnosis and Treatment. Edited by B Hilman. (Pp 953; £148 hardback.) Harcourt Brace Jovanovich, 1993. ISBN 0-7216-4683-2.

This is a major textbook on paediatric chest disease, of similar size to Kendig. There are 97 chapters and 127 contributors, all but two from North America. Chapters are grouped into sections. The first called 'general information' has five chapters: pulmonary mechanics, pulmonary defences, respiratory mucous, epidemiology, and self management programmes. The second considers evaluation and includes diagnostic methods. The last called 'management' includes chapters on environmental control, surgical procedures, ventilatory support and resuscitation, and several chapters on drug pharmacology. The remainder consider disease categories. Each section is amply supported by diagrams, graphs, tables, radiographs, lists, and drawings. References up to 1991 are in the Vancouver style.

One striking omission is the exclusion of the management of respiratory infection in the developing world. The World Health Organisation recently claimed that its much publicised acute respiratory infection programme has resulted in a $25 \%$ reduction in mortality. If true this huge advance in the care of respiratory disease in children is surely worth mentioning. Diphtheria, another major disease with a huge mortality, is not mentioned at all.

This textbook compares very well with Kendig, a valuable source of references and information. But should a textbook not also be a learning tool? The problem with texts written by so many authors is that while all 